\title{
Princípios da Responsabilidade Social Empresarial nas Relações "Empresa-Stakeholders" como Fonte de Vantagem Competitiva ${ }^{1}$
}

\author{
Principles of Corporate Social Responsibility in Relations "Firm- \\ Stakeholders" as source of Competitive Advantage
}

\section{Principios de Responsabilidad Social en las relaciones de la compañía "Partes Interesadas" como una fuente de ventaja competitiva}

\author{
Maria José da Silva Feitosa, MSc. \\ Universidade Federal Rural de Pernambuco \\ Endereço: Unidade Acadêmica de Serra Talhada \\ (UAST). Fazenda Saco, Apoio Didático II, Bloco 03, \\ Térreo. CEP: 56.909-460 - Serra Talhada, PE, Brasil. \\ Telefone: (87) 3929-3212, e-mail: \\ mariafeitosa.ufrpe@gmail.com
}

\author{
Natália Mary Oliveira de Souza, MSc. \\ Programa de Pós-Graduação em Administração \\ (PROPAD) - Universidade Federal de Pernambuco \\ Faculdade de Filosofia, Ciências e Letras de Caruaru \\ Endereço: Rua José Gomes de Moura, 538. Estância. \\ Recife/PE, Brasil. Telefone: (81) 3251-9262, e-mail: \\ natalia.o.souza@gmail.com
}

\author{
Carla Regina Pasa Gómez, Dr ${ }^{\text {a }}$ \\ Programa de Pós-Graduação em Administração (PROPAD) - UFPE \\ Endereço completo: Rua dos Economistas, S/N. \\ Centro de Ciências Sociais Aplicadas, Campus da UFPE. \\ Telefone: (81) 2126-7167, e-mail: carlapasagomez@gmail.com
}

\section{RESUMO}

Devido à intensa competitividade empresarial, as organizações passaram a visualizar nas relações com todos os seus stakeholders a oportunidade de alcançar vantagem competitiva, visto que estes estão dispostos a reconhecer e recompensar o comportamento ético, transparente e solidário das empresas. Parte-se da premissa que a intensidade das relações e a proximidade dos atores na rede de relações empresa-stakeholders podem proporcionar uma eficiente disseminação dos princípios da Responsabilidade Social Empresarial (RSE) ao longo dessa rede e, portanto, o alcance de vantagem competitiva. Baseando-se nessas considerações, o presente ensaio questiona: como a inserção dos princípios da Responsabilidade Social Empresarial nas relações "empresa-stakeholders", pode contribuir para o alcance da vantagem competitiva? Para tanto, a partir de uma pesquisa bibliográfica, o estudo propõe um framework que integra as relações "empresa-stakeholders", RSE e vantagem competitiva. Pretende-se comprovar que a RSE, permeada na transparência das relações entre empresas e stakeholders, constitui-se em fonte de vantagem competitiva. Os resultados do estudo apontam que redes relacionais densas entre empresa central e stakeholders podem gerar uma vantagem competitiva total, enquanto que, em outro extremo, uma empresa com baixa centralidade alocada em uma rede pouco densa apresentará desvantagem competitiva total. Dessa forma, as empresas que não

\footnotetext{
${ }^{1}$ Artigo recebido em 15.06.2013. Revisado pelos pares em 10.12.2013 (blind review). Ajustado e Aceito para publicação em 25.02.2014. Recomendado para publicação por José Ribamar Marques de Carvalho (Editor Científico). Publicado em 10.04.2014. Organização responsável UACC/CCJS/UFCG.
} 
se preocupam em desenvolver relações estreitas, intensas e honestas com outros atores sociais podem sucumbir no mercado competitivo.

Palavras-chave: Stakeholders, Responsabilidade Social Empresarial, Vantagem Competitiva.

\begin{abstract}
Because of intense business competition, firms start to perceive in relations with all stakeholders the opportunity of to achieve competitive advantage, because they are willing to recognize and pay back ethical, transparent and solidary behavior of the firms. In this context, the centrality and density measures are used to express how intense or incipient are the relationship between firms and its stakeholders, as well to show the proximity or distance the firms are in relationship network with stakeholders. This relations intensity and this proximity between stakeholders in the network relationship will provide an efficient dissemination of CSR principles all over this network and, thus, get competitive advantage. According these considerations, this paper has the following problem: how the inclusion of the corporate social responsibility principles in relationships between "firms - stakeholders" can contribute to the achievement of competitive advantage? So, based on a literature researcha, the study aims to suggest a framework that integrates the relationships "firms - stakeholders" with CSR. The main conclusions of the study point out those dense relational networks between central firm and stakeholders can generate a total competitive advantage, while a firm with low centrality situated in a not much dense network will result in total competitive disadvantage.
\end{abstract}

Key-words: Stakeholders, Corporate Social Responsibility, Competitive Advantage.

\title{
RESUMEN
}

Dada la intensa competitividad empresarial, las organizaciones visualizan en las relaciones con sus stakeholders la oportunidad de obtener ventajas competitivas, una vez que los stakeholders están dispuestos a reconocer y recompensar el comportamiento ético, transparente y solidario de las empresas. Partiendo de la premisa de que la intensidad de las relaciones y la proximidad de los actores en la red de relacionamiento empresa-stakeholder pueden promocionar una eficiente difusión de los principios de la Responsabilidad Social de las Empresas (RSE) a lo largo de esta red $y$, por lo tanto, obtener ventajas competitivas. Basados en estas consideraciones, este artículo formula la siguiente pregunta: ¿Cómo la inclusión de los principios de la Responsabilidad Social Empresarial en las relaciones "empresas-stakeholders" pueden contribuir para el alcance de ventajas competitivas? Teniendo en cuenta los aportes teóricos se presenta un marco que integra las relaciones entre ellos. Con esto se pretende comprobar que la RSE es la clave para promocionar la transparencia de las relaciones que se establecen entre ellos y que apuntan para la ventaja competitiva. Los resultados de estos estudios apuntan que las redes de relaciones densas entre empresa central y sus stakeholders pueden generar una ventaja competitiva total, por otro lado en otro extremo una empresa con baja centralidad en una red poco densa presentara desventaja competitiva total. Así, las empresas que no se preocupan en desarrollar relaciones estrechas, intensas y sinceras con otros actores sociales pueden desaparecer del mercado.

Palabras-clave: Stakeholders. Responsabilidad social empresarial. Ventajas competitivas.

\section{INTRODUÇÃO}

Em função da intensa competitividade empresarial, as organizações começaram a perceber que apenas a relação com os acionistas não seria suficiente para garantir a vantagem competitiva no mercado. Atrelada à elevação da competitividade surgem pressões por parte dos diversos stakeholders - a exemplo de 
funcionários, governo, ONGs, clientes, comunidade etc. - os quais, ao acessarem quantidades significativas de informação a respeito da realidade empresarial e possuírem consciência de seu poder de mercado, passaram a demandar práticas mais responsáveis por parte das empresas.

$\mathrm{O}$ acesso da maior parte da população à informação acerca dos problemas sociais e ambientais proporcionou a politização dos cidadãos, os quais passaram a exigir das empresas a elaboração de produtos e serviços levando em consideração valores sociais e ambientais. Consequentemente, o público começou a demandar das organizações maior envolvimento, no que diz respeito à solução dos problemas de ordem social e ambiental (KRUGLIANSKAS; ALIGLERI; ALIGLERI, 2009).

Esses acontecimentos contribuíram para que houvesse o estreitamento nas relações empresa-stakeholders, como forma de possibilitar benefícios para ambas as partes. Como resultado, as empresas passam a atender aos interesses desses atores, por meio do comportamento ético, transparente e socialmente responsável.

Em decorrência do surgimento de novos contextos empresariais, caracterizados por turbulências e incertezas, as organizações alteram seus propósitos e métodos organizacionais como forma de alinhá-los aos anseios da sociedade. Assim, o desempenho econômico favorável e a sustentabilidade empresarial dependem da maneira como a organização se relaciona com os seus stakeholders (KRUGLIANSKAS; ALIGLERI; ALIGLERI, 2009).

Assim, a Responsabilidade Social Empresarial (RSE) emerge como um mecanismo que, uma vez inserido na rede de relações que existe entre as empresas e seus stakeholders, pode promover vantagem competitiva. No entanto, para que esta venha a existir é necessário que as referidas relações sejam intensas.

A intensidade dos relacionamentos em uma rede pode ser vislumbrada por meio das medidas de estrutura de rede e de posição dos atores na rede de relações, sendo tais medidas denominadas densidade e centralidade, respectivamente.

Com base nessas considerações, o presente estudo visa solucionar o seguinte problema de pesquisa: como a inserção dos princípios da Responsabilidade Social Empresarial nas relações "empresa-stakeholders", pode contribuir para o alcance da vantagem competitiva?

Para responder ao problema de pesquisa, o presente estudo visa propor um framework que integre as "relações empresa-stakeholders" com Responsabilidade Social Empresarial, integrando Teoria da rede de influências dos stakeholders proposta por Rowley (1997) - com a Teoria referente ao elo entre vantagem competitiva e responsabilidade social empresarial, proposta por Porter e Kramer (2006).

O presente trabalho justifica-se na medida em que amplia e, concomitantemente, aprofunda o arcabouço teórico-conceitual da ciência administrativa, por meio de um framework que agrega constructos distintos, em uma lógica de entendimento integrada, legitimando a condição de interdisciplinaridade da ciência administrativa nas organizações. 
Além disso, trará considerável contribuição prática, visto que possibilitará a efetivação de pesquisas empíricas, que visem verificar as relações propostas no framework e, dessa forma, munir os gestores de informações ao longo do processo de tomada de decisão.

Diante do exposto, este trabalho encontra-se assim estruturado: em um primeiro momento será apresentada uma discussão sobre a teoria dos stakeholders, destacando-se o modelo de influências dos stakeholders, proposto por Rowley (1997). Em seguida, será abordada a temática referente à RSE e Vantagem Competitiva. Posteriormente, o framework será apresentado. Por fim, seguem as considerações finais e as referências bibliográficas.

\section{EMBASAMENTO TEÓRICO}

\subsection{Teoria dos stakeholders}

Por muitos anos, acadêmicos e gestores consideraram os acionistas como os stakeholders mais importantes no que tange ao desempenho da organização. No entanto, novas perspectivas acadêmicas e pressões de outros indivíduos ou grupos vêm alterando a relação entre a empresa e a sociedade. De acordo com Borger (2001), é ampla a quantidade de agentes que se relaciona com a empresa. A Figura 01 ilustra alguns dos principais agentes vinculados à organização.

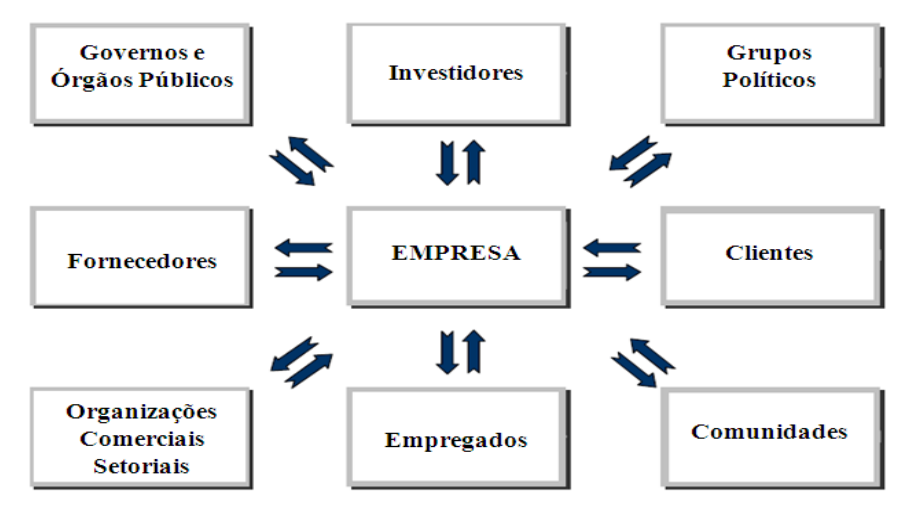

Figura 01: a corporação e seus stakeholders

Fonte: Donaldson e Preston (1995)

Com base na Figura 01, as exigências para com a empresa são advindas de diversas partes (consumidores, colaboradores, governo, fornecedores e sociedade etc.), as quais têm levado as empresas a adotarem comportamentos que correspondam às expectativas destes atores (DONALDSON; PRESTON, 1995; FREEMAN, 1994). Estes estão direta ou indiretamente vinculados às atividades da organização, sendo denominados stakeholders.

Para Freeman (2010, p.46), stakeholders podem ser definidos como "qualquer grupo ou indivíduo que pode afetar ou é afetado pela realização dos objetivos da 
organização". Nessa linha de raciocínio, Mitchell, Agle e Wood (1997) afirmam que pessoas, grupos, comunidades, organizações, instituições, sociedades, são considerados stakeholders reais ou potenciais. De outro modo, são agentes que se relacionam direta ou indiretamente com a organização.

É interessante que esse relacionamento ocorra por meio do estabelecimento de objetivos conjuntos, compartilhamento de informações e recursos, assim como da luta integrada pelo alcance de soluções. Dessa forma, as partes serão beneficiadas e desenvolve-se uma relação baseada na confiança, na integridade e na credibilidade, os quais são valores importantes na constituição de um ambiente de confiança, troca e participação dos stakeholders (BORGER, 2001).

Esse foco orientado para as relações das empresas com seus agentes envolvidos ainda é carente de estudos, já que parte significativa das investigações volta-se para classificação dos agentes. Segundo Rowley (1997), a partir do lançamento do livro "Strategic Management: a Stakeholder Approach", proposto por R. Edward Freeman, em 1984, muitos estudiosos começaram a desenvolver teorias sobre stakeholders, concentrando-se na classificação destes em categorias que fornecem uma compreensão de como eles influenciam as operações das empresas.

Porém, poucos estudos visam entender como as empresas respondem às influências dos stakeholders (ROWLEY, 1997). Utilizando conceitos de análises de redes sociais, Rowley (1997) desenvolveu um modelo que identifica alguns comportamentos relacionados à resistência das empresas às pressões dos stakeholders.

\subsection{Relação empresa-stakeholders conforme Rowley (1997)}

As relações dos stakeholders ocorrem em uma rede de influências, pelas quais tais atores podem manter relação direta entre si. Os pesquisadores estão cada vez mais utilizando a análise de redes sociais para ampliar a compreensão de diversos fenômenos comportamentais e sociais. A abordagem de análise de redes tem importância para pesquisadores, uma vez que eles podem usá-la para examinar os elementos centrais da perspectiva dos stakeholders (ROWLEY, 1997).

Comentando o trabalho de Rowley (1997), Fallon (2008) aponta que as relações dos stakeholders podem ser complexas, e totalmente confusas. Especialmente quando stakeholders podem ter expectativa de se relacionar com outros stakeholders.

O foco principal da análise de redes sociais é a interdependência dos atores e como estes se posicionam nessas redes de influência, bem como suas oportunidades, restrições e comportamentos. Assim, as redes podem ser compreendidas como um grupo de atores que se relacionam, com uma determinada finalidade, caracterizandose pela existência de fluxos de informações.

As redes são compostas por três elementos básicos, quais sejam: "nós" ou atores, vínculos ou relações e, fluxos. Atores são pessoas ou organizações que se agrupam por um objetivo comum. Vínculos são laços que existem entre os atores. E fluxos indicam a direção do vínculo entre os atores (ALEJANDRO; NORMAN, 2005). 
Nessa perspectiva, a análise de redes sociais vem sendo estudada na literatura para explicar comportamentos e processos sociais. Os indicadores de densidade e centralidade são as principais ferramentas que contribuem para analise das redes, permitindo considerações sobre a estrutura da rede, assim como a posição dos atores na rede, respectivamente.

A densidade mede o número relativo de laços entre os atores em uma rede. Tal indicador é calculado como sendo a razão de um número de relacionamentos existentes na rede, comparado com o número total de possíveis laços que podem existir nesta (ROWLEY, 1997).

Duas características da densidade são importantes para examinar as respostas organizacionais às pressões dos stakeholders, a saber: (1) o aumento da densidade possibilita a troca de informações por toda a rede, tornando a comunicação eficiente; (2) redes densas difundem normas, valores e padrões comportamentais entre seus atores. Portanto, redes densas tendem a resultar em pressões dos stakeholders sobre as ações das organizações, visando tornar o comportamento destas em conformidade com os objetivos da rede (ROWLEY, 1997).

Complementando o entendimento de Rowley (1997), Gilsing et. al (2008) apontam que uma rede densa facilita o acúmulo de confiança, a qual pode ser considerada um mecanismo de reputação e coligações para restringir o oportunismo. Dessa forma, a alta densidade global da rede desempenha um papel importante no que diz respeito à avaliação da confiabilidade de fontes de inovação, bem como à compreensão e avaliação dessas fontes.

Um caso de rede com alta densidade é apresentado por Tauhata e MacedoSoares (2004). Ao realizarem um estudo na Companhia Vale do Rio Doce, esses autores mostram que a referida empresa está inserida em uma rede composta por parceiros com alto status. Além disso, de acordo com esses autores, a empresa também mantém fortes laços com clientes e concorrentes. Essas são características de uma rede com alta densidade.

Outro indicador importante para a análise das redes trata-se da centralidade, a qual tem o intuito de identificar a posição de um ator em relação aos outros atores. A centralidade de rede está relacionada à importância dos atores em uma rede social e ao poder que um ator exerce sobre os demais. De acordo com Rossoni e Guarido Filho (2007), quanto mais centrais os atores em uma rede maior importância têm tais atores. A companhia Vale do Rio Doce é uma organização central, na medida em que possui recursos valiosos e difíceis de imitar. Conforme Tauhata e Macedo-Soares (2004) esses recursos são tanto físicos quanto intangíveis - capital informacional pertinente a clientes reais e potenciais, know-how tecnológico e mercadológico.

Três tipos de centralidade são discutidos na literatura: centralidade de grau, de intermediação e de proximidade (ROWLEY, 1997; ROSSONI; GUARIDO FILHO, 2007; COX; MELO; RÉGIS, 2009). A centralidade de grau refere-se ao número de vínculos que um ator possui com outros em uma rede (MARTINS; CSILLAG; PEREIRA, 2009; WASSERMAN; FAUST, 1994; COX; MELO; RÉGIS, 2009). Dessa 
forma, atores com alta centralidade de grau terão acesso a muitas fontes alternativas de informação e recursos (ROWLEY, 1997).

A alta centralidade de grau pode ser visualizada, por exemplo, quando em um processo de comunicação em uma rede social, uma pessoa está em uma posição que a possibilita contatar diretamente várias outras, de modo que ela passa a se enxergar e ser enxergada pelas outras pessoas como o maior canal de comunicação (COX; MELO; RÉGIS, 2009). Nessa linha de raciocínio, estes autores explicam que um ator com baixo grau de centralidade se percebe e é percebido pelos outros atores de forma periférica, isto é, sua posição o isola do direto envolvimento com a maior parte dos outros atores na rede, deixando-o fora da participação ativa no processo de comunicação.

Já a centralidade de intermediação refere-se ao ator cuja função é interligar atores periféricos, os quais são caracterizados por não apresentarem conexão direta. Sendo assim, atores intermediários controlam atores periféricos (TOMAÉL; MARTELETO, 2006). Corroborando Tomaél e Marteleto (2006), Gilsing et al. (2008), destacam que empresas com alta centralidade de intermediação tornam-se melhor informadas sobre o que está acontecendo na rede, aumentando as possibilidades das empresas centrais formarem novos vínculos relacionais. Além disso, essa interação permite acesso rápido a informações importantes e inovadoras, bem como maior status e poder.

A centralidade de intermediação pode ser vislumbrada, por exemplo, quando no processo de comunicação em uma rede social, uma pessoa que está entre outras duas, torna possível a comunicação entre estas pelo menor caminho que as conecta. Seguindo essa interpretação, Cox, Melo e Régis (2009) esclarecem que a centralidade de intermediação visualiza um ator numa posição beneficiada, uma vez que este ator se encontra no caminho menor entre as partes e outros atores na rede. Isso implica dizer que o ator que está na posição favorecida tem poder em relação às demais, visto que estas dependem da primeira para realizar conexões com os outros atores da rede. Uma pessoa com elevado poder de intermediação atua como guardião de informações que fluem ao longo da rede (COX; MELO; RÉGIS, 2009).

A centralidade de proximidade, por sua vez, refere-se à distância de um ator em relação a outros na rede. Assim, quanto mais próximo um ator estiver de outros atores, mais central ele estará, representando independência em relação aos atores intermediários, e significando menos transmissões de mensagens, tempos menores e custos mais baixos no que concerne ao recebimento de informações e recursos (TOMAÉL; MARTELETO, 2006). Corroborando estes autores, Cox, Melo e Régis (2009) apregoam que a independência de um ator é estabelecida pela proximidade que ele mantém em relação a todos os outros atores na rede. Quanto mais perto estiver um ator de todos os outros atores na rede, menor será a dependência e, consequentemente, maior será a centralidade de intermediação.

Explicando de formas clara e objetiva os tipos de centralidade, Freeman (1979) assume que quando um ator demonstra interesse na atividade de comunicação, 
ocorre centralidade de grau; já quando o ator almeja o controle da comunicação, observa-se a intermediação; e o interesse por independência e eficiência do processo comunicativo, representa a centralidade de proximidade.

Assim, no que tange à centralidade, é necessário considerar que, se por um lado, o ator tem acesso a uma grande diversidade de informações que circulam na rede, por outro, o mesmo não tem capacidade para absorver todas as informações relevantes. Já no caso da densidade, apesar da rede ter capacidade de absorver todo conhecimento, este perde a condição de novidade, pois todos os atores têm acesso às informações que adentram na rede.

Para resolver esse impasse, Gilsing et al. (2008) propõem que alta densidade pode ser compensada pela alta centralidade de intermediação. A interação entre centralidade de intermediação e densidade tem um efeito positivo para empresa, que resulta de uma constante busca por novos conhecimentos e absorção destes, assim como pela busca de novas oportunidades. Nesse sentido, Rowley (1997) afirma que a interação da densidade e centralidade da empresa produz diferentes tipos de estruturas de rede, que influenciam o equilíbrio de poder relativo entre a empresa e seus stakeholders, conforme o Quadro 01.

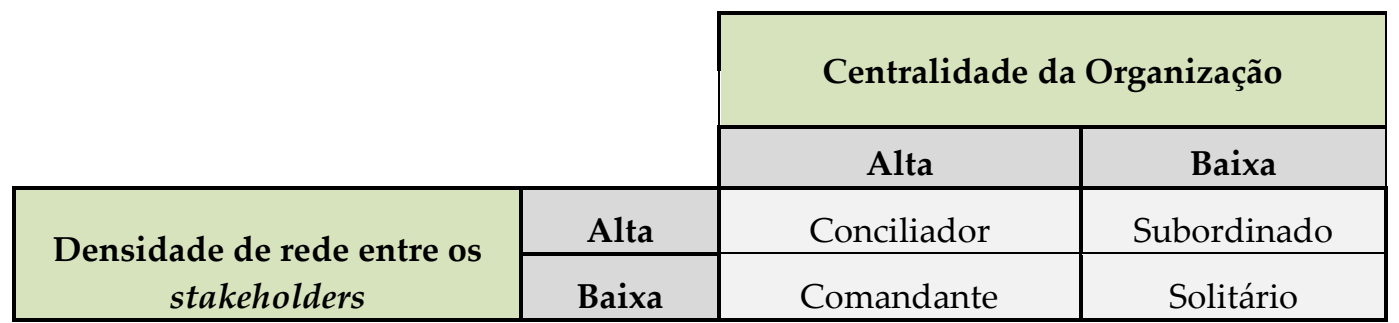

Quadro 01: Estrutura de influência e respostas das organizações às pressões dos stakeholders Fonte: Rowley (1997)

A partir do Quadro 01, constata-se que em uma rede com alta densidade, os atores sociais são capazes de restringir as ações da empresa a qual estão vinculados, podendo coordenar seus esforços para controlar e punir a organização. Por outro lado, se há na rede uma empresa central (com alta centralidade), esta poderá influenciar os fluxos de informação e a formação das expectativas, sendo capaz de resistir às pressões dos seus stakeholders. Dessa forma, a organização central em rede densa se tornará conciliadora, tentando se equilibrar, pacificar e negociar com seus stakeholders influentes uma posição satisfatória (ROWLEY, 1997).

Assim, diz-se que em rede com alta densidade os atores interagem intensamente, compartilhando informações, construindo normas compartilhadas, monitorando informações e orientando o fluxo dessas.

Já no caso de alta centralidade e baixa densidade, a organização é capaz de resistir às pressões dos stakeholders, pois, nesse caso, detém recursos raros e informações importantes. Uma rede de baixa densidade impede os fluxos de informação - já que a interação entre os atores é reduzida -, os esforços de monitoramento e formação de normas compartilhadas. Assim, a empresa irá adotar 
um papel de comandante, tentando controlar os fluxos de informação, as trocas de recursos na rede e constituir normas compartilhadas (ROWLEY, 1997). Em outras palavras, a empresa consegue dominar e orientar os fluxos de informação na rede, já que detém recursos difíceis de imitar e seu poder de negociação é superior aos dos demais stakeholders presentes na rede.

Uma rede com alta densidade contraposta a uma organização apresentando baixa centralidade cria uma estrutura de rede que permite a comunicação eficiente entre os stakeholders, de modo que a organização torna-se incapaz de influenciar o processo de troca de informações, devido sua posição periférica. Consequentemente, uma empresa com baixa centralidade em uma rede com alta densidade passará a ser subordinada aos stakeholders, aceitando as normas estabelecidas e agindo em conformidade com as expectativas destes (ROWLEY, 1997). Assim, quando uma empresa desprovida de competências distintivas e recursos informacionais raros (know-how, capital intelectual, por exemplo), se insere em uma rede muito densa, isto é, com compartilhamento de informações intenso, ela (a empresa) poderá ter dificuldades na relação com os stakeholders, visto que estes mantêm o domínio da rede e têm intenso poder de negociação em relação à empresa.

Por fim, em uma situação em que há baixas densidade e centralidade, a organização não é capaz de manipular as normas estabelecidas, visto que não ocupa uma posição influente na rede. Como resultado, a empresa adota um papel solitário, ocultando suas atividades, dissimulando condutas e não atendendo às demandas e exigências dos stakeholders. Não há elevada incidência desse tipo de organização, uma vez que as empresas, para sobreviverem, necessitam de recursos oriundos da interação com outras organizações (ROWLEY, 1997).

Independente do poder de influência dos stakeholders ou da relevância dos mesmos, todos os tipos de atores devem ser monitorados pela empresa. É da responsabilidade dos gestores selecionar atividades e direcionar recursos para obter benefícios dos stakeholders (DONALDSON; PRESTON, 1995). Esses benefícios podem ser obtidos a partir da adoção de práticas de RSE, as quais, segundo o Instituto Ethos (2008), têm ganhado importância como atributo diferencial de competitividade.

\subsection{Responsabilidade Social Empresarial e Vantagem Competitiva}

A intensa competitividade, bem como o crescente aumento das exigências sociais e ambientais no que tange à atuação responsável no contexto empresarial, fomentou nas organizações o interesse pelo desenvolvimento de práticas que preservem de forma sistêmica o interesse daqueles que - direta ou indiretamente estão envolvidos em suas atividades.

Nesse sentido, Maloni e Brown (2006) apontam que organizações podem ser consideradas socialmente e eticamente responsáveis por uma grande variedade de stakeholders, tais como: clientes, empregados, governos comunidades, ONGs, investidores, membros da cadeia de suprimentos, órgãos governamentais e a mídia. 
FEITOSA, M. J. da S.; et al. Princípios da Responsabilidade Social Empresarial...

Todavia, para serem consideradas socialmente e eticamente responsáveis, as organizações necessitam integrar os princípios de RSE com o core business da organização (SOUSA FILHO; WANDERLEY; GÓMEZ, 2010).

A RSE é o modo de gestão definido pelas relações éticas, transparentes e responsáveis da empresa com todos os seus stakeholders, bem como pela determinação de metas empresarias alinhadas aos princípios do desenvolvimento sustentável, que presa pela utilização dos recursos ambientais e culturais no presente, sem impossibilitar as próximas gerações de usufruir de tais recursos (EUROPEAN COMISSION, 2002; LEANDRO; RABELO, 2011; RAMACHANDRAN, 2010).

Nessa perspectiva, o compromisso para RSE passa a ser vislumbrada como um importante pilar no que tange aos ganhos de parceria e a confiança dos públicos, atrelado ao reconhecimento que pode fortalecer a posição de mercado da companhia e seu compromisso com uma abordagem competitiva sustentável (MIRON; PECTU; SOBOLEVSCHI, 2011).

Almejando atender essa diversidade de interesses, as organizações desenvolvem ações que suprem, por um lado, às demandas ambientais e sociais e, por outro, alavancam o desempenho empresarial no mercado, em decorrência da boa aceitação de seus produtos e serviços por parte da sociedade, a qual passa a atribuir valor às empresas que os integram os princípios da RSE no core business, garantindo que as atividades econômicas organizacionais apresentem um impacto ambiental e social positivos.

$\mathrm{Na}$ medida em que alinham crescimento econômico e aumento da competitividade com proteção ambiental e equidade social, as organizações estão contribuindo para o desenvolvimento sustentável (EUROPEAN COMISSION, 2002; KRUGLIANSKAS; ALIGLERI; ALIGLERI, 2009). Logo, desenvolve-se uma relação simbiótica, na qual o sucesso da empresa e o sucesso da sociedade se reforçam, gerando um valor mútuo, de modo que quanto mais ligada estiver a questão social com o negócio da empresa, maior a oportunidade de alavancar os recursos e capacidades da empresa, e beneficiar a sociedade (PORTER; KRAMER, 2006; LEANDRO; RABELO, 2011). Em outras palavras, é possível equacionar desempenho empresarial e bem estar social, desde que as relações entre as organizações e a sociedade sejam pautadas no equilíbrio de benefícios entre as partes.

Para Kruglianskas, Aligleri e Aligleri (2009), a responsabilidade social das empresas é indissociada do conceito de sustentabilidade, de modo que analisar as políticas socioambientais de uma organização a possibilita avaliar seu desempenho sustentável na sociedade e para a sociedade.

Nessa perspectiva, a RSE ganha caráter estratégico e passa a ser vislumbrada como elemento imprescindível (vital) para organizações em todos os países (MINTZBERG, 1983; PEARCE; DOH, 2005; PORTER; KRAMER, 2006; SOUSA FILHO; WANDERLEY; GÓMEZ, 2010). Ademais, é fonte de oportunidades, inovação e vantagem competitiva (HUSTED; ALLEN, 2001; PORTER; KRAMER, 
2006). Para Barney (1991) há vantagem competitiva sustentável quando uma empresa operacionaliza uma estratégia de criação de valor, que não é concomitantemente implementada por todos os atuais ou potenciais competidores.

No entanto, há certa dificuldade em obter vantagem competitiva sustentável, uma vez que a RSE é pautada no princípio da transparência das práticas empresariais. Este percalço é superado quando a RSE passa compor a cultura e dos valores de uma organização. De acordo com Leandro e Rabelo (2011) apregoam que quando a RSE é encarada em um sentido mais amplo, é algo que envolve toda empresa. A RSE não será ampla e plena enquanto não estiver absorvida nas práticas dos indivíduos que trabalham na e com a empresa que assume esta postura.

Para Leandro e Rabelo (2011) há clara sobreposição RSE e Cultura organizacional que deve ser estudada para que se apure as práticas de RSE podem imbuir-se na cultura de uma organização e, a seu tempo, corporizar uma cultura de responsabilidade social.

Para Barney (1991) valores organizacionais são aceitos como recursos intangíveis que podem resultar em vantagem competitiva. Uma vez disseminados na organização tais valores passam a integrar as relações empresa-stakeholders, tornando mais sólida a vantagem competitiva, notadamente, se houver intensidade nas relações.

Neste contexto, Castelo Branco e Rodrigues (2006) e Dyer e Singh (1998) argumentam que boas relações entre empresa e stakeholders possibilitam o desenvolvimento de valiosos ativos intangíveis (não físicos), que podem ser fonte de vantagem competitiva e tornar a empresa distinta de seus concorrentes. Recursos intangíveis como, por exemplo, cultura corporativa e boa reputação são construidos a partir de relações intensas e estreitas entre a empresa e seus stakeholders.

Portanto, as organizações devem canalizar esforços para o constante desenvolvimento de relações com o público envolvido em suas atividades, pois assim a disseminação dos princípios da RSE ocorrerá de maneira eficiente e, por conseguinte, a vantagem competitiva será alcançada. Ratificando tal pressuposto, Hillman e Keim (2001) asseguram que ao se relacionar com os stakeholders, as empresas devem enfatizar as interações relacionais, pois estas não são facilmente duplicada.

Toda essa discussão evidencia a importância da RSE, como um mecanismo capaz de elevar o desempenho empresarial no mercado na medida em que, se gerida corretamente, pode promover vantagem competitiva. Esse gerenciamento implica em inserir e alinhar os princípios da RSE pregados pela empresa com os valores daqueles com os quais mantém relações, ou seja, seus stakeholders, em um fluxo contínuo e constante de relações. Assim, quanto mais intensas e duradouras forem as relações maior a vantagem competitiva ou vantagem de relacionamento (DYER; SINGH; 1998)

É a partir dessa lógica de compreensão, isto é, da inserção e alinhamento das diretrizes da RSE na rede de relacionamentos, como elemento impulsionador da 
vantagem competitiva empresarial, que foi elaborado um framework que integra a Responsabilidade Social Empresarial nas relações empresa-stakeholders, como forma de alcançar vantagem competitiva. A seguir, serão apresentadas, por meio de uma seção de metodologia, as etapas utilizadas no processo de elaboração do framework proposto.

\section{PROCEDIMENTOS METODOLÓGICOS}

Este ensaio teórico foi induzido, incicialmente, pelas ideias centrais presentes nos estudos de Porter e Kramer (2006) e de Rowley (1997). Os dois primeiros autores buscaram descrever a ligação existente entre a vantagem competitiva e a responsabilidade social empresarial, Rowley (1997), por sua vez, desenvolveu uma estrutura de influência e respostas das organizações às pressões dos stakeholders, utilizando, para tanto, os conceitos de densidade e centralidade de redes sociais. As etapas necessárias para a elaboração deste estudo estão esquematizadas na Figura 02, a seguir.

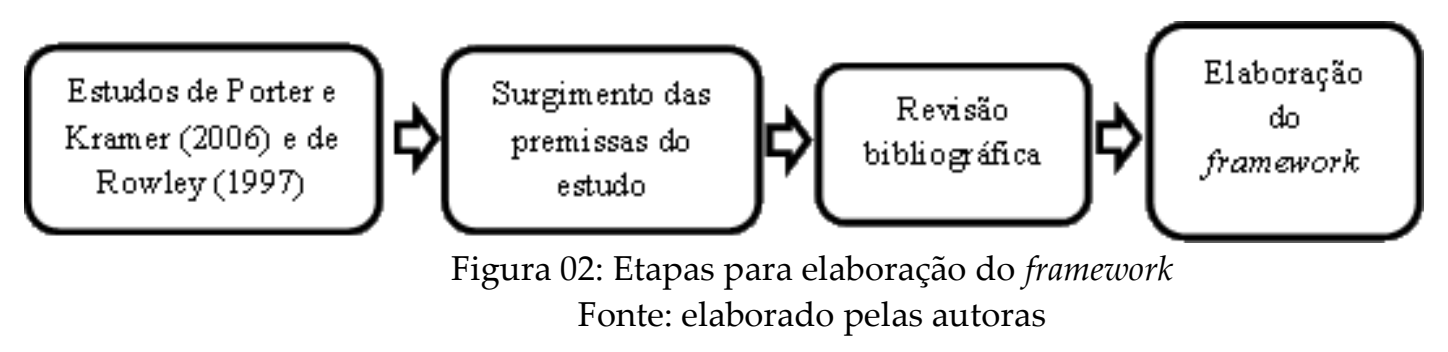

Como pode ser observado na Figura 02, após a revisão dos estudos citados no parágrafo anterior, desenvolveu-se algumas premissas, dentre as quais: a intensidade das relações e a proximidade dos atores na rede de relações empresa-stakeholders proporcionará uma eficiente disseminação dos princípios da Responsabilidade Social Empresarial (RSE) ao longo dessa rede e, portanto, o alcance de vantagem competitiva. A RSE é vista como resultante de pressões advindas dos stakeholders e seus princípios, que envolvem ética, transparência nas relações, bem como cuidado e respeito com o meio ambiente e com a sociedade, podem resultar em vantagens, tais quais: relações estreitas e de longo prazo com os atores sociais, além da garantia de recursos materiais e sociais no futuro.

Destarte, predominam nessa premissa as seguintes temáticas: RSE, vantagem competitiva, teoria dos stakeholders e redes sociais, as quais guiaram a revisão bibliográfica deste ensaio. A revisão bibliográfica permitiu o esclarecimento das ideias iniciais, bem como apresentou discussões relevantes para a construção do framework. Algumas dessas ideias estão apresentadas no Quadro 02, a seguir. 
FEITOSA, M. J. da S.; et al. Princípios da Responsabilidade Social Empresarial...

\begin{tabular}{|l|l|}
\hline \multicolumn{1}{|c|}{ Ideias Centrais } & \multicolumn{1}{|c|}{ Autores } \\
\hline $\begin{array}{l}\text { As exigências para com a empresa são advindas de } \\
\text { diversos atores sociais, os quais têm levado as empresas a } \\
\text { adotarem comportamentos que correspondam às } \\
\text { expectativas destes atores }\end{array}$ & $\begin{array}{l}\text { Donaldson e Preston } \\
\text { (1995); Freeman (1994) }\end{array}$ \\
\hline $\begin{array}{l}\text { Para serem consideradas socialmente e eticamente } \\
\text { responsáveis, as organizações necessitam integrar os } \\
\text { princípios de RSE com o core business da organização }\end{array}$ & $\begin{array}{l}\text { Souza Filho, Wanderley e } \\
\text { Gómez (2010) }\end{array}$ \\
\hline $\begin{array}{l}\text { O desempenho econômico favorável e a sustentabilidade } \\
\text { empresarial dependem da maneira como a organização se } \\
\text { relaciona com os seus stakeholders }\end{array}$ & $\begin{array}{l}\text { Kruglianskas, Aligleri e } \\
\text { Aligleri (2009) }\end{array}$ \\
\hline $\begin{array}{l}\text { Ao se relacionar com os stakeholders, as empresas devem } \\
\text { enfatizar as interações relacionais, pois estas não são } \\
\text { facilmente duplicadas }\end{array}$ & Hillman e Keim (2001) \\
\hline $\begin{array}{l}\text { A interação da densidade e centralidade da empresa } \\
\text { produz diferentes tipos de estruturas de rede, que } \\
\text { influenciam o equilíbrio de poder relativo entre a empresa } \\
\text { e seus stakeholders }\end{array}$ & Rowley (1997) \\
\hline $\begin{array}{l}\text { O compromisso para RSE passa a ser vislumbrada como } \\
\text { um importante pilar no que tange aos ganhos de parceria e } \\
\text { a confiança dos públicos, atrelado ao reconhecimento que } \\
\text { pode fortalecer a posição de mercado da companhia e seu } \\
\text { compromisso com uma abordagem competitiva } \\
\text { sustentável }\end{array}$ & $\begin{array}{l}\text { Miron, Pectu e } \\
\text { Sobolevschi (2011) }\end{array}$ \\
$\begin{array}{l}\text { Quanto mais ligada estiver a questão social com o negócio } \\
\text { da empresa, maior a oportunidade de alavancar os } \\
\text { recursos e capacidades da empresa, e beneficiar a } \\
\text { sociedade }\end{array}$ & $\begin{array}{l}\text { Porter e Kramer (2006); } \\
\text { Leandro e Rabelo (2011) }\end{array}$ \\
\hline $\begin{array}{l}\text { A RSE ganha caráter estratégico, sendo fonte de } \\
\text { oportunidades, inovação e vantagem competitiva }\end{array}$ & $\begin{array}{l}\text { Dyer e Singh (1998); } \\
\text { Husted e Allen (2001); } \\
\text { Castelo Branco e } \\
\text { Rodrigues (2006); } \\
\text { Porter e Kramer (2006); } \\
\text { Sousa Filho, Wanderley e } \\
\text { Gómez (2010) }\end{array}$ \\
\hline
\end{tabular}

Quadro 02: Ideias centrais $x$ autores

Fonte: elaborado pelas autoras

As ideias exibidas no Quadro acima foram úteis para unir a teoria da RSE como fonte de vantagem competitiva à teoria da estrutura de influência e respostas das organizações às pressões dos stakeholders. A partir de tais processos, o framework proposto foi construido com o objetivo de esclarecer como a inserção dos princípios da Responsabilidade Social Empresarial, nas relações "empresa-stakeholders", pode contribuir para o alcance da vantagem competitiva. O framework, que integra as temáticas estudadas, será apresentado e discutido na seção seguinte. 
FEITOSA, M. J. da S.; et al. Princípios da Responsabilidade Social Empresarial...

\section{Apresentação dos Resultados}

\subsection{RSE, Relações "empresa-stakeholders" e Vantagem Competitiva: proposição de um framework integrador}

O framework apresentado a seguir, emergiu a partir de insights resultantes da integração de aspectos teóricos atinentes à teoria de stakeholders; à Responsabilidade Social Empresarial com foco estratégico; e às medidas de densidade e centralidade, que representam, respectivamente, a quantidade de vínculos entre os atores na rede e a posição desses atores na rede.

A partir do framework é possível explicar como a inserção e disseminação dos princípios da responsabilidade social empresarial na rede de relacionamentos "empresa-stakeholders" contribui para o alcance de vantagem competitiva.

Nesse contexto, as medidas de centralidade e densidade servem para mostrar o quão intensas ou incipientes são as relações entre a empresa e seus stakeholders (densidade), bem como quão próximos ou distantes estão as empresas na rede de relacionamentos com os stakeholders (centralidade). É essa intensidade de relações e essa proximidade dos atores na rede de relações que proporcionará uma eficiente disseminação dos princípios da RSE ao longo dessa rede e, portanto, o alcance de vantagem competitiva.

Nessa perspectiva, duas condições devem ser atendidas para que seja possível o alcance de vantagem competitiva através da RSE. São elas: (1) os princípios da RSE devem estar disseminados na rede de relacionamentos; (2) a empresa deve manter relações intensas e estreitas com os demais atores da rede.

Atendendo essas duas condições, a vantagem competitiva é estabelecida, uma vez que os princípios da RSE, disseminados de forma intensiva na rede, farão parte de todas as relações empresa-stakeholders e, nesse caso, as referidas partes manterão relacionamentos saudáveis, decorrentes de um atendimento mútuo de interesses.

No entanto, em função da dinamicidade do framework proposto, é possível que, em algum momento, essas duas condições não sejam completamente atendidas. Ocasionalmente, é provável que a rede de relacionamentos apresente alta densidade e baixa centralidade e vice versa. Nesse caso, considerando a existência dos princípios na rede (condição primordial), haverá uma vantagem competitiva parcial.

Outra situação que pode ocorrer é a baixa centralidade e baixa densidade. Desse modo, mesmo que a condição primordial seja atendida, isto é, mesmo que os princípios estejam disseminados na rede, não haverá vantagem competitiva, tendo em vista que os princípios da RSE não farão parte da relação empresa-stakeholders.

Todas essas considerações anteriormente mencionadas podem ser visualizadas a seguir na Figura 03, a qual evidencia o alcance de vantagem competitiva a partir da difusão dos ideais da RSE na rede de relações da empresa ou grupo de empresas com seus stakeholders. 


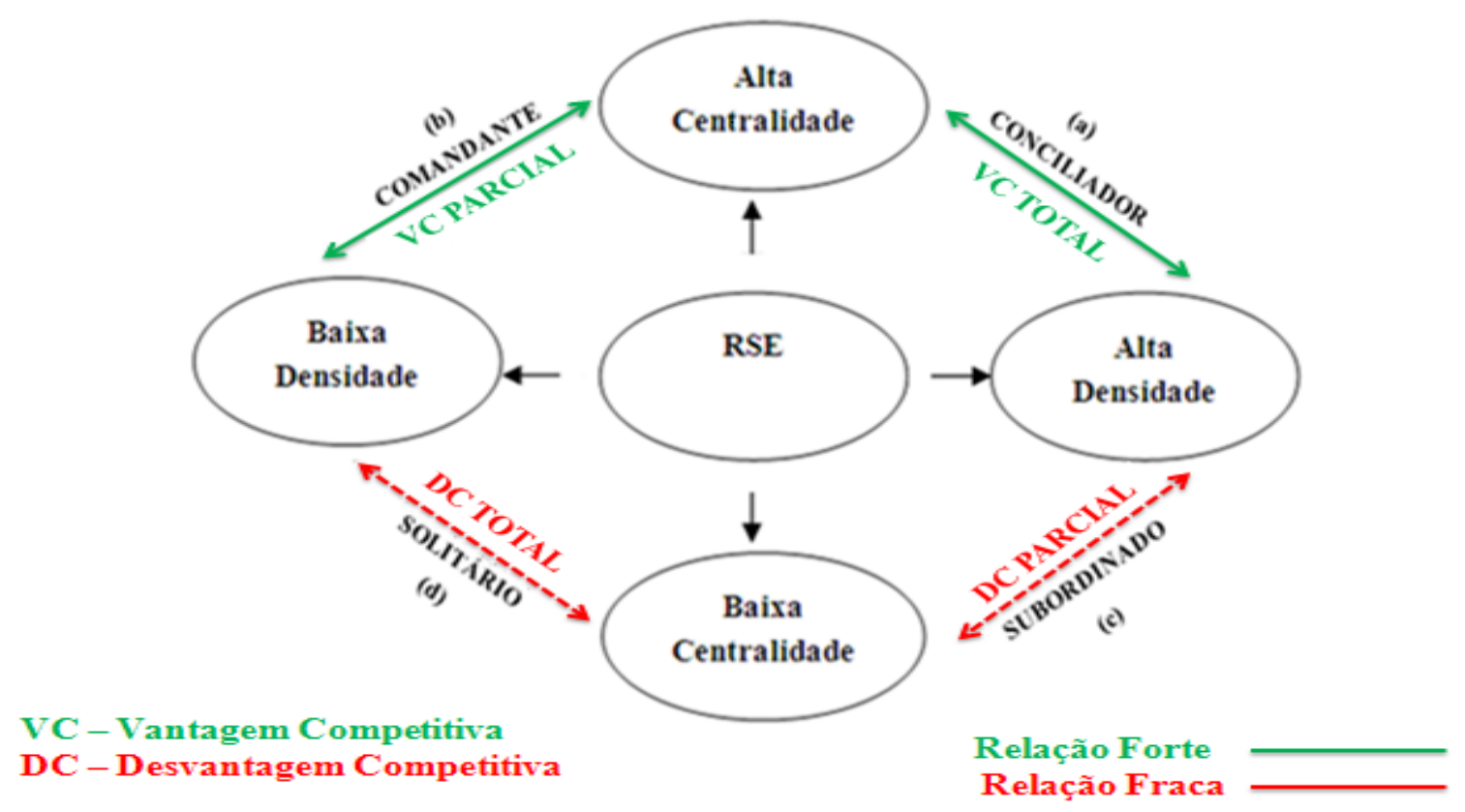

Figura 03: Framework integrando RSE, relações "empresa-stakeholders" e vantagem competitiva Fonte: elaborado pelas autoras com base nas teorias apresentadas

Com base na Figura 03, infere-se que na situação (a) na qual a rede é densa e a empresa possui alta centralidade, os stakeholders coordenam seus esforços para exigir das empresas práticas de RSE. As empresas com alta centralidade, caracterizadas como conciliadoras, procuram negociar com os stakeholders de forma que ambos sejam favorecidos. O que ocorre nessa relação é o aumento da confiança entre empresa-stakeholders, criando, portanto, um valor intrínseco para empresa, permeado pelos princípios da RSE e que garante a fidelidade dos stakeholders e a, consequente, vantagem competitiva total.

No caso (b) em que a empresa possui alta centralidade, mas a densidade da rede é baixa, a organização adquire o comportamento de comandante. A empresa pode influenciar o fluxo de informações e as normas compartilhadas em uma rede, podendo optar por não adotar as práticas de RSE nas relações com os stakeholders. Porém, a relação desenvolvida entre empresa-stakeholders não envolverá confiança e fidelidade, ocasionando em uma vantagem competitiva parcial. Em longo prazo, outra empresa que adote efetivamente os princípios de RSE pode vir a fazer parte desta rede de relacionamento e tornar-se central, adquirindo para si a vantagem competitiva.

Na circunstância (c), empresas com baixa centralidade e imersas em redes altamente densas, na qual os stakeholders exigem que as empresas pratiquem a responsabilidade social, são subordinadas as normas e expectativas impostas pelos stakeholders. Todavia, se a empresa adota os princípios e prática a Responsabilidade Social Empresarial (RSE) exigida, poderá adquirir legitimidade e poder, vindo a ser 
um ator central na rede e, eventualmente, adquirindo vantagem competitiva. Diz-se que há desvantagem competitiva parcial por a situação de subordinado não ser permanente.

Por fim, na situação (d), empresas com baixa centralidade, presentes em redes com baixa densidade, são caracterizadas por serem solitárias, suas atividades passam por despercebidas, não atendendo as necessidades e exigências de seus stakeholders quanto à RSE. Dessa forma, este tipo de organização não sobreviverá por muito tempo, possuindo, então, desvantagem competitiva total.

\section{CONSIDERAÇÕES FINAIS}

A rivalidade empresarial exige das firmas respostas estratégicas direcionadas ao alcance de vantagem competitiva. Uma maneira de alcançar esse tipo de vantagem frente à concorrência está na adoção de práticas de RSE que, se verificadas nas relações "empresa- stakeholders", presentes em rede de relacionamentos de alta densidade, possibilitam confiança, respeito e fidelidade, os quais são aspectos importantes para o alcance de desempenho empresarial positivo.

Assim, o desempenho empresarial positivo varia em função da intensidade de relações (densidade), bem como da proximidade (centralidade) que a empresa mantém com seus stakeholders. Isso implica na formação de uma rede intensa de relacionamentos que favorece tanto a empresa quanto os atores que estão direta ou indiretamente envolvidos com ela. No cenário competitivo, as empresas devem, no mínimo, criar e manter relações com os diversos atores sociais para garantir a sobrevivência no mercado, pois, assim como a sociedade depende das empresas, estas dependem da sociedade para obter os recursos (humanos, materiais, financeiros etc.) necessários para garantir a atuação das empresas.

Por meio dos resultados, foi observado que em um extremo a alta densidade e centralidade em uma rede permeada pela RSE pode permitir uma vantagem competitiva total, no outro extremo, a baixa densidade e baixa centralidade acarretará em uma desvantagem competitiva total. Dessa forma, no primeiro caso é possível que a relação desenvolvida envolva confiança e respeito mútuo, permitindo a fidelização de consumidores, que, satisfeitos, disseminam e fortificam a imagem da empresa, bem como permitem a atração de novos consumidores. No segundo caso, as empresas não se preocupam em desenvolver relações com os stakeholders, muitas vezes dissimulando comportamentos e obtendo rejeição dos atores sociais.

Nota-se, então, que quando os princípios da RSE existem na relação empresastakeholders a rede de relacionamentos se fortifica, devido a confiança e a troca entre os atores, e se amplia, visto que novos participantes são atraídos pela reputação positiva da empresa. Nessa perspectiva de entendimento, o framework proposto torna-se inovador, representando a interação de teorias, com o intuito de enriquecer o conhecimento das ciências empresariais. Além disso, foi possível explicar como a RSE constitui-se em fonte de vantagem competitiva. 
É relevante salientar, contudo, que o estudo não foi embasado em evidências empíricas, e sim por meio apenas da revisão da literatura, sendo essa a principal limitação do estudo. Uma contribuição prática poderá ser obtida a partir da realização de um estudo empírico, o qual possibilitará identificar ou não nas empresas o comportamento refletido no esquema proposto. Assim sendo, sugere-se a aplicação do framework em diferentes tipos de empresas, sobretudo, nas que já adotam os princípios de RSE, pois dessa forma, será possível verificar se a forma como esses princípios estão sendo disseminados na rede de relações, está gerando ou não vantagem competitiva. Sugere-se, ainda, estudos que evidenciem a percepção dos stakeholders sobre práticas socialmente responsável das empresas.

\section{REFERÊNCIAS}

ALEJANDRO, V. A.; NORMAN, A. G. 2005. Estado de México - UAEM Universidad Autonoma Del Estado De Mexico, p. 1-36.

BARNEY, J. 1991. Firm Resources and Sustained Competitive Advantage. Journal of Management. 17 (1): 99-120.

BORGER, F. G. 2001. Responsabilidade social: efeitos da atuação social na dinâmica empresarial. São Paulo, SP. Tese de Doutorado, Universidade de São Paulo (USP), 254p.

CASTELO B., M.; RODRIGUES, L. L. 2006. Corporate social responsibility and resource-based perspectives. Journal of Business Ethics, 69 (2): 111-132.

COX, M.; MELO, P. T. N. B.; RÉGIS, H. P. 2009. Posições centrais em uma rede social. Gestão Contemporânea, Porto Alegre, 6 (6): 69-96.

DONALDSON, T.; PRESTON, L.E. 1995.The stakeholder theory of the corporation: Concepts, evidence, and implications. Academy of Management Review, 20:65-91.

DYER, J. H.; SINGH, H. 1998. Cooperative Strategy and Sources of Interorganizational Competitive Advantage. The Academy of Management Review, 23(4): 660-679.

COMMISSION OF THE EUROPEAN COMMUNITIES. 2002. Corporate Social Responsibility - A Business Contribution to Sustainable Development (Office for Official Publications of the European Communities, Luxemburg). 1-24. 
FEITOSA, M. J. da S.; et al. Princípios da Responsabilidade Social Empresarial...

FALLON, W. J. 2008. Stakeholder participation and corporate social responsibility: a critical study of problem gambling in the new south wales registered club sector. University of Western Sydney. Doctoral Thesis. 341 p.

FREEMAN, R. E. 2010. Strategic Management: a Stakeholder Approach. New York: Cambridge University Press. Disponível em: $<$ http://books.google.com.br/books?id=NpmA_qEiOpkC\&printsec=frontcover\&dq=St rategic+Management:+a+Stakeholder+Approach\&hl=ptBR\&ei=bXL_TYWgFuTo0QG $\mathrm{V} 2 \mathrm{rWzAw \& sa}=X \&$ oi=book_result\&ct $=$ result\&resnum $=1 \& \mathrm{ved}=0 \mathrm{CC0Q6AEwAA} \# \mathrm{v}=$ on epage\&q\&f=false

> Acesso em: 11 de junho de 2011.

FREEMAN, R. E. 1994. The politics of stakeholders theory: some future directions. In: DIENHART, J. W. (Ed.). Business Ethics Quarterly, 4 (4): 409-422.

FREEMAN, L. C. 1978/1979. Centrality in social networks: conceptual clarification. Social Networks, n. 1, p. 215-239.

GILSING, V.; NOOTEBOOM, B.; VANHAVERBEKE, W.; DUYSTERS, G. 2008. Network embeddedness and the exploration of novel technologies: technological distance, betweenness centrality and density. Research Policy, 37(10): 1717-1731.

HILLMAN, A. J.; KEIM, G. D. 2001. Shareholder Value, Stakeholder Management, and Social Issues: What's the Bottom Line?. Strategic Management Journal, v. 22, n. 2, p. $125-139$

HUSTED, B. W.; ALLEN, D. B. 2001. Toward a model of corporate social strategy formulation. Paper presented at the social issues in Managament Division at Academy of Management, 2-35. Washington, August.

INSTITUTO ETHOS DE EMPRESAS E RESPOSANBILIDADE SOCIAL. 2006. Critérios Essenciais de Responsabilidade Social Empresarial e seus mecanismos de indução no Brasil. Disponível em: <http://www.uniethos.org.br/_Uniethos/Documents/criterios_essenciais_web.pdf> Acesso em: 26 maio de 2011.

KRUGLIANSKAS, I.; ALIGLERI, L.; ALIGLERI, L. A. 2009. Gestão socioambiental: responsabilidade e sustentabilidade do negócio. São Paulo: Atlas, 245 p. 
FEITOSA, M. J. da S.; et al. Princípios da Responsabilidade Social Empresarial...

LEANDRO, A. RABELO, T. 2011. A responsabilidade social das empresas: incursão ao conceito e suas relações com a cultura organizacional. Comunicação nas Organizações (exedra), número especial, p. 11-39.

MALONI, J. M.; BROWN, E. M. 2006. Corporate Social Responsibility in the Supply Chain: An Application in the Food Industry. Journal of Business Ethics, 68 (1): 35-52.

MARTINS, M. E.; CSILlAG, J. M.; PEREIRA, S. C. F. 2009. A produção e a colaboração científica em operações de serviços: uma análise da rede internacional de pesquisadores e instituições. In: XII SIMPÓSIO DE ADMINISTRAÇÃO DA PRODUÇÃO, LOGÍSTICA E OPERAÇÕES INTERNACIONAIS, São Paulo, 2009. Anais... São Paulo, 1-17.

MINTZBERG, H. 1983. The case for corporate social responsibility. Journal of Business Strategy, 4 (2): 3-15.

MIRON, D.; PECTU, M.; SOBOLEVSCHI, I. M. 2011. Corporate social responsibility and the sustainable competitive advantage. AE - Amfiteatru Economic, 13(29):162-179.

MITCHELL, R. L.; AGLE, B. R.; WOOD, D. J. 1997. Towards a theory of stakeholder identification and salience deifing the principle of who and what really counts. Academy of Management, 22 (4):853-886.

PEARCE, J. A. II.; DOH, J. P. 2005. The high impact of collaborative social initiatives. MITSloan Management Review, 46(3): 29-39.

PORTER, M. E.; KRAMER, M. 2006. Strategy and society: the link between competitive advantage and corporate social responsibility. Harvard Business Review, p. 78-92.

RAMACHANDRAN, V. 2010. Strategic Corporate Social Responsibility: A 'Dynamic Capabilities' Perspective. 18: p. 285-293.

ROSSONI, L.; GUARIDO FILHO, E. R. 2007. Cooperação interinstitucional no campo da pesquisa em estratégia. Revista de Administração de Empresas, 47 (4):72-86.

ROWLEY, T. J. 1997. Moving beyond Dyadic Ties: A Network Theory of Stakeholder Influences. The Academy of Management Review, 22 (4): 887-910.

SOUSA FILHO, J. M.; WANDERLEY, L. S. O.; GÓMEZ, C. P. 2010. Strategic Corporate Social Responsibility Management for Competitive Advantage. Brazilian Administration Review, 7 (3): 294-309. 
FEITOSA, M. J. da S.; et al. Princípios da Responsabilidade Social Empresarial...

TAUHATA, T. L.; MACEDO-SOARES, T. D. L. v. A. de. 2004. Rede e alianças estratégicas no Brasil: caso CVRD. Revista de Administração de Empresas-eletrônica, $3(1), 1-23$.

TOMAÉL, M. I.; MARTELETO, R. M. 2006. Redes Sociais: Posições dos atores no fluxo da informação. Encontros Bibli: revista eletrônica em Ciência da Informação, edição especial, p. 75-91.

WASSERMAN, S.; FAUST, K. 1994. Social network analysis: methods and applications. Cambridge: Cambridge University Press. 8: 857 p. 